\title{
Effects of age, sex, and ethnicity on bone health status of the elderly in Kuala Lumpur, Malaysia
}

This article was published in the following Dove Press journal:

Clinical Interventions in Aging

13 June 2016

Number of times this article has been viewed

\author{
Kok-Yong Chin' \\ Alia Annessa Ain \\ Kamaruddin ${ }^{2}$ \\ Nie Yen Low ${ }^{2}$ \\ Soelaiman Ima-Nirwana' \\ 'Department of Pharmacology, \\ Faculty of Medicine, Universiti \\ Kebangsaan Malaysia Medical Centre, \\ Cheras, Kuala Lumpur, ${ }^{2}$ ASASIpintar, \\ PERMATApintar National Gifted \\ Centre, Universiti Kebangsaan \\ Malaysia, Bangi, Selangor, Malaysia
}

\begin{abstract}
Background: Osteoporosis is a significant health problem in the developing countries and its prevalence data are important for the estimation of health care burden and policy making. This study aimed to determine the age-related changes in bone health and the prevalence of osteoporosis in males and females aged 50 years or above living in Kuala Lumpur, Malaysia.

Methods: A cross-sectional study was conducted between December 2014 and December 2015. Subjects answered a demographic questionnaire and underwent body anthropometric and bone health measurement. Assessment of bone health was performed using a quantitative ultrasound device that generated speed of sound, broadband ultrasound attenuation, stiffness index, and T-score based on stiffness index value as bone health indices.

Results: The prevalence of osteoporosis was $10.6 \%$ in males and $8.0 \%$ in females. Significant age-related decline of bone health indices (speed of sound, broadband ultrasound attenuation, stiffness index, and T-score) and a concurrent increase in the prevalence of osteoporosis and osteopenia were observed in females $(P<0.05)$ but not in males $(P>0.05)$. Ethnic differences in bone health indices and prevalence of osteoporosis/osteopenia were not observed $(P>0.05)$.

Conclusion: A significant proportion of males and females age 50 years or above have suboptimal bone health. Preventive measures such as early screening should be implemented to retard the progression of osteoporosis.
\end{abstract}

Keywords: aging, osteopenia, osteoporosis, prevalence, T-score

\section{Introduction}

Osteoporosis is a systemic metabolic bone disease defined by low bone mass and disintegration of bone microarchitecture, leading to bone fragility and ultimately fracture. ${ }^{1}$ Clinically, osteoporosis is diagnosed based on bone mineral density (BMD) determined using dual-energy X-ray absorptiometry (DEXA) because it is predictive of fracture. ${ }^{2}$ However, accessibility to DEXA is limited especially in the developing countries. ${ }^{4}$ Quantitative ultrasound (QUS) devices offer a solution to this problem. Bone health indices generated by QUS were found to correlate significantly with BMD and fracture risk..$^{5-8}$ The QUS device is safe, easy to handle, and portable, thus, permitting its use in mass screening of bone health and epidemiological studies. ${ }^{9}$

The effects of age and sex in bone health are well documented. Incidence of fragility fractures increases and BMD declines with advancing age. ${ }^{10,11}$ Global prevalence of fragility fracture showed a female-to-male ratio of 7 to $3 .^{12}$ This is in accord with a higher BMD and QUS values found in males compared to females. ${ }^{13,14}$ Ethnicity is also an important determinant of bone health. This is evidenced by the significant ethnic disparity in the prevalence of osteoporosis among the Non-Hispanic Whites, African Americans, and Hispanics in the US. ${ }^{14,15}$ Survey on hip fracture incidence among Malaysian populations consisting of the Chinese, Malays, and Indians also revealed distinct ethnic differences. ${ }^{10}$
Correspondence: Soelaiman Ima Nirwana Department of Pharmacology, Faculty of Medicine, Universiti Kebangsaan Malaysia Medical Centre, Jalan Yaacob Latif, 56000 Cheras, Kuala Lumpur, Malaysia

Tel +6039 |45 5002

Fax +60391456633

Email imasoel@ppukm.ukm.edu.my
Clinical Interventions in Aging 2016:1 | 767-773

767

Dovepress

$f y$ in 0

http://dx.doi.org/10.2147ICIA.S108772

(c) (1) $\odot 2016$ Chin et al. This work is published and licensed by Dove Medical Press Limited. The full terms of this license are available at https://www.dovepress.com/terms.php (c) ${ }_{\mathrm{BY}} \mathrm{NC}$ and incorporate the Creative Commons Attribution - Non Commercial (unported, v3.0) License (http://(creativecommons.org/licenses/by-nd/3.0/). By accessing the work you hereby accept the Terms. Non-commercial uses of the work are permitted without any further permission from Dove Medical Press Limited, provided the work is properly attributed. For permission for commercial use of this work, please see paragraphs 4.2 and 5 of our Terms (https://www.dovepress.com/terms.php). 
Several small-scale bone health studies have been conducted in Malaysia using QUS devices in females and a study has been performed in males. ${ }^{17-20}$ Subjects included in these studies were not reflective of the Malaysian population because they captured bone health in a limited subset of the diverse ethnic groups in Malaysia. ${ }^{21}$ Since the report of Lee and Khir on hip fracture incidence in $1997,{ }^{10}$ more comprehensive and updated data on ethnic difference in bone health in Malaysia are not available. In bridging the knowledge gap, we could identify groups susceptible to osteoporosis and device suitable interventions to retard the progression of the disease.

The current study aimed to determine the age-related changes and prevalence of osteoporosis and osteopenia in males and females aged 50 years or above in Kuala Lumpur, Malaysia. Three major ethnic groups, that is, the Malays, Chinese, and Indians, representing $99.3 \%$ of the Malaysian population will be included in this study. ${ }^{21}$ A calcaneal QUS device was selected as the bone health screening tool as per the recommendation of the International Society of Clinical Densitometry. ${ }^{22}$ Males and females aged 50 years or above were the focus of this study because previous studies highlighted that fracture incidence increased after the age of 50 years. ${ }^{12}$ We hypothesized that there were significant age-related changes and ethnic discrepancy in bone health in the Malaysian population.

\section{Materials and methods}

This cross-sectional study was conducted from December 1, 2014 to November 31, 2015 at Universiti Kebangsaan Malaysia Medical Centre. A purposive sampling method was adopted and subjects recruited were Malaysian males and females aged 50 years old or above living in Kuala Lumpur and its environs. The subjects were solicited onsite without prior invitation. Subjects previously diagnosed with osteoporosis, hyper/hypoparathyroidism, or hyper/hypocalcaemia and/or were receiving pharmacological treatment for osteoporosis (bisphosphonates, teriparatide, denosumab, and strontium ranelate) or other treatments, which could significantly impact bone metabolism (hormone-replacement therapy, sex hormone deprivation therapy, glucocorticoids, and thyroid supplements) were excluded. Those with mobility problems, with implant in their lower limbs, or could not complete the questionnaire or screening procedure were excluded as well. The subjects were informed of the project details and provided written consent before participating in the study. The study protocol was reviewed and approved by the Research Ethics Committee of Universiti Kebangsaan Malaysia Medical Centre (approval code: UKM-AP-TKP-09-2009).
Subjects completed a demographic questionnaire before undergoing the screening process. The age of the subjects was calculated based on records in their identification cards. Ethnicity, sex, and presence of preexisting medical condition(s) and medical treatment(s) were self-declared. Standing height of the subjects without shoes was measured using a stadiometer (Seca, Hamburg, Germany) and recorded to the nearest $1 \mathrm{~cm}$. Body weight of subjects with light clothing but without shoes was determined using a weighing scale (Tanita, Tokyo, Japan) and was recorded to the nearest $0.1 \mathrm{~kg}$. Body mass index (BMI) was calculated as per the convention. Bone health of the subjects was assessed using a water-based QUS device (Achilles EXPII, GE Healthcare UK Ltd, Little Chalfont, UK). During the scanning, the subjects were required to sit on a chair and place their right foot on the food pad. The inflatable transducer transmitted ultrasound waves across the right calcaneal bone and the signal received was measured and analyzed. Subjects were measured three times with repositioning and the average values were taken. Trained technicians were responsible for the measurements. Quality control and calibration were performed daily using a phantom. Short-term in vivo coefficient of variation for the device was $<2.0 \%$. The device generated three bone health indices, namely, speed of sound (SOS), broadband ultrasound attenuation (BUA), and stiffness index (SI). Calcaneal SOS is the SOS waves traveling though the calcaneus and bears the unit of meter per second $(\mathrm{m} / \mathrm{s})$. The SOS value is directly proportional to BMD value. Calcaneal BUA is the slope between attenuation of sound signals while traveling through the calcaneus and its frequency and the unit is $\mathrm{dB} / \mathrm{MHz}$. Stronger bones preferentially attenuate sound waves of higher frequencies. SI combines SOS and BUA values using the formula $\mathrm{SI}=([0.67 \times \mathrm{BUA}]+[0.28 \times$ SOS] -420) and has a lower precision error than either SOS or BUA alone. In general, higher SOS, BUA, and SI values indicate better bone health. ${ }^{9,23}$

T-score generated based on the SI was used as the basis for bone health classification. It is different from T-score based on BMD obtained from DEXA, which is used to diagnose osteoporosis clinically. In this study, bone health of subjects was classified into normal (T-score more than -1.0), osteopenia ( $\mathrm{T}$-score between -2.5 and -1.0 ), and osteoporosis (T-score less than -2.5 ) based on sex-specific reference values obtained from Mainland Chinese population provided by the manufacturer due to the absence of local reference. The term "normal" indicated a low risk for osteoporosis, "osteopenia" indicated a moderate risk for osteoporosis, and "osteoporosis" indicated a high risk for osteoporosis. 


\section{Statistical analysis}

Normality of the data was assessed using KolmogorovSmirnov test. Skewed data were transformed for analysis. Subjects were categorized according to age groups (5 years interval), sex, and ethnicities for the comparison of bone health indices. Comparison of characteristics between male and female subjects was performed using independent $t$-test. Comparison of bone health indices between ethnicities and age groups was performed using univariate analysis with adjustment for BMI. Pair-wise comparison of bone health indices between selected age groups was done using Gabriel's post hoc test. The BMI adjusted age-trend of all three bone health indices was examined using multiple linear regression analysis. Age and BMI were entered into the multiple regression analysis via the forced entry method. Differences in the proportion of subjects in each bone health category according to sex, ethnicity, and age group were analyzed using chi-square. Significance value was set at $P<0.05$. Statistical analysis was performed using Statistical Package for Social Science Version 21 (IBM Corporation, Armonk, NY, USA).

\section{Results}

A total of 772 male and female subjects enrolled in this study, but 127 were excluded based on the exclusion criteria (40 for the use of hormone-replacement therapy, 30 for the use of antiosteoporotic agents, eleven for the use of glucocorticoid, 44 for the use of thyroid supplement, and two did not complete the screening process). The 645 subjects included in the final analysis consisted of 283 males (mean age: 63.38 years [standard deviation (SD): 7.41 years]) and 362 females (mean age: 61.69 years [SD: 7.52 years]). Ethnic distribution for males was $38.9 \%$ Malays, $49.5 \%$ Chinese, and $11.7 \%$ Indians, while for females was $34.3 \%$ Malays, $57.5 \%$ Chinese, and $8.3 \%$ Indians. The males were significantly older, taller, and heavier, and had a higher BMI compared to
Table I Basic characteristics of the subjects

\begin{tabular}{|c|c|c|c|c|c|}
\hline \multirow[t]{2}{*}{ Variables } & \multirow{2}{*}{$\frac{\text { Male }}{\text { Mean }}$} & \multirow{2}{*}{$\frac{(n=283)}{S D}$} & \multirow{2}{*}{$\frac{\text { Female }}{\text { Mean }}$} & \multirow{2}{*}{$\frac{(n=362)}{S D}$} & \multirow[t]{2}{*}{$P$-value } \\
\hline & & & & & \\
\hline Age (years) & 63.38 & $7.4 I$ & 61.69 & 7.52 & 0.004 \\
\hline Height (cm) & 165.87 & 7.21 & 153.70 & 5.64 & $<0.001$ \\
\hline Weight (kg) & 71.07 & 12.32 & 60.36 & 11.25 & $<0.001$ \\
\hline BMI & 25.95 & 4.20 & & 4.67 & 0.307 \\
\hline $\operatorname{SOS}(\mathrm{m} / \mathrm{s})$ & $\mathrm{I}, 544.45$ & 37.01 & $1,535.39$ & 37.76 & 0.009 \\
\hline $\mathrm{BUA}(\mathrm{dB} / \mathrm{MHz})$ & 119.33 & 12.85 & 112.65 & 13.26 & $<0.001$ \\
\hline SI & 91.33 & 17.80 & 84.67 & $|8.2|$ & $<0.001$ \\
\hline T-score & -1.04 & 1.68 & -0.66 & 1.67 & 0.002 \\
\hline
\end{tabular}

Abbreviations: BMI, body mass index; BUA, broadband ultrasound attenuation; SD, standard deviation; Sl, stiffness index; SOS, speed of sound.

females $(P<0.05)$. Their SOS, BUA, and SI values were also higher compared to females after adjusted for BMI $(P<0.05)$. However, their BMI-adjusted T-score was significantly lower compared to their female counterparts $(P<0.05)$ (Table 1).

Age-related decline in bone health, as indicated by SOS, BUA, SI, and T-score, was significant in females but not in males. The values of these indices started to decrease significantly at the age of 65 years for females $(P<0.05)$. In comparison, the bone health indices of males did not show significant age trend $(P>0.05)$. The results persisted after adjustment for BMI of the subjects (Table 2). No significant association was found between age and indices of bone health in males as a whole and among the different ethnic groups after adjustment for BMI in the linear regression analysis $(P>0.05)$. On the other hand, there were significant negative associations between age and indices of bone health in females $(P<0.05)$. As the age increased by 1 year, the SOS reduced by $1.136 \mathrm{~m} / \mathrm{s}$, BUA by $-0.438 \mathrm{~dB} / \mathrm{MHz}$, SI by 0.607 unit, and T-score by 0.06 unit in females as a whole. Similar decline was observed in Malay and Chinese females but not in Indian females probably due to the small sample size of that particular ethnic group (Table 3).

Table 2 Body mass index-adjusted bone health indices according to age group

\begin{tabular}{|c|c|c|c|c|c|c|c|c|c|c|c|c|c|c|c|c|c|c|}
\hline \multirow{3}{*}{ Age group } & \multicolumn{9}{|c|}{ Male } & \multicolumn{9}{|c|}{ Female } \\
\hline & \multirow[t]{2}{*}{$\mathbf{n}$} & \multicolumn{2}{|c|}{$\operatorname{sos}(\mathrm{m} / \mathrm{s})$} & \multicolumn{2}{|c|}{$\begin{array}{l}\text { BUA } \\
\text { (dB/MHz) }\end{array}$} & \multicolumn{2}{|l|}{ SI } & \multicolumn{2}{|c|}{ T-score } & \multirow[t]{2}{*}{$\mathbf{n}$} & \multicolumn{2}{|l|}{$\operatorname{sos}(\mathrm{m} / \mathrm{s})$} & \multicolumn{2}{|c|}{$\begin{array}{l}\text { BUA } \\
\text { (dB/MHz) }\end{array}$} & \multicolumn{2}{|l|}{ SI } & \multicolumn{2}{|l|}{ T-score } \\
\hline & & Mean & SD & Mean & SD & Mean & SD & Mean & SD & & Mean & SD & Mean & SD & Mean & SD & Mean & SD \\
\hline 50-54 years & 37 & $1,544.20$ & 5.84 & 118.21 & 11.37 & 91.00 & 17.40 & -1.04 & 1.34 & 69 & $1,547.00$ & 28.99 & 116.99 & 11.05 & 90.68 & 14.29 & -0.06 & 1.41 \\
\hline $55-59$ years & 45 & I,552.46 & 5.54 & 120.08 & 11.87 & 94.56 & 18.18 & -0.78 & 1.41 & 93 & I,537.03 & 30.09 & 113.06 & 11.48 & 85.63 & 14.85 & -0.59 & 1.45 \\
\hline 60-64 years & 81 & $|, 546.5|$ & 4.08 & 119.90 & 11.79 & 91.92 & 17.91 & -1.00 & $\mathrm{I} .44$ & 89 & I,538.09 & 29.34 & 113.08 & 11.13 & 86.21 & 14.43 & -0.52 & 1.42 \\
\hline $65-69$ years & 65 & I,537.58 & 4.65 & 117.09 & 12.01 & 88.00 & 18.30 & -1.33 & 1.45 & 53 & $\mathrm{I}, 530.1 \mathrm{I}^{\mathrm{a}}$ & 28.83 & $111.57^{a}$ & 10.99 & $82.5 \mathrm{I}^{\mathrm{a}}$ & 14.20 & $-0.83^{a}$ & 1.38 \\
\hline 70-74 years & 32 & $1,545.96$ & 6.22 & $|21.3|$ & 11.26 & 93.42 & 17.20 & -0.87 & 1.36 & 36 & $\mathrm{I}, 522.65^{\mathrm{a}}$ & 28.38 & $107.52^{\mathrm{a}}$ & 10.80 & $77.99^{\mathrm{a}, \mathrm{c}}$ & 13.98 & $-1.36^{a, b, c}$ & 1.38 \\
\hline $\begin{array}{l}75 \text { years or } \\
\text { above }\end{array}$ & 23 & I,548.2I & 7.31 & 121.74 & 11.22 & 94.90 & 17.12 & -0.84 & 1.34 & 23 & $|, 5| 7.06^{\mathrm{a}, \mathrm{b}, \mathrm{c}}$ & 28.20 & $103.42^{\mathrm{a}, \mathrm{b}, \mathrm{c}}$ & 10.74 & $73.56^{\mathrm{a}, \mathrm{b}, \mathrm{c}}$ & 13.91 & $-1.79 \mathrm{a}, \mathrm{b}, \mathrm{c}$ & 1.39 \\
\hline
\end{tabular}

Notes: Alphabets indicate significant difference between the denoted group with ${ }^{\mathrm{a}} 50-54$ years; ${ }^{\mathrm{b}} 55-59$ years; ‘ $60-64$ years.

Abbreviations: BUA, broadband ultrasound attenuation; SD, standard deviation; SOS, speed of sound. 
Table 3 Body mass index-adjusted association between age and bone health indices

\begin{tabular}{|c|c|c|c|c|c|c|c|c|c|c|c|c|}
\hline \multirow[t]{2}{*}{ Ethnicity, sex } & \multicolumn{3}{|c|}{ SOS $(\mathrm{m} / \mathrm{s})$} & \multicolumn{3}{|c|}{ BUA (dB/MHz) } & \multicolumn{3}{|l|}{ SI } & \multicolumn{3}{|c|}{ T-score } \\
\hline & B & SE & $P$-value & B & SE & $P$-value & B & SE & $P$-value & B & SE & $P$-value \\
\hline Malay, male & -0.160 & 0.516 & 0.756 & 0.056 & 0.151 & 0.711 & -0.038 & 0.232 & 0.870 & -0.002 & 0.019 & 0.927 \\
\hline Chinese, male & -0.477 & 0.323 & 0.142 & -0.019 & 0.114 & 0.869 & -0.127 & 0.157 & 0.420 & -0.015 & 0.012 & 0.218 \\
\hline Indian, male & 0.713 & 0.963 & 0.465 & 0.401 & 0.294 & 0.184 & 0.424 & 0.470 & 0.374 & 0.041 & 0.038 & 0.290 \\
\hline Overall, male & -0.152 & 0.274 & 0.578 & 0.076 & 0.086 & 0.380 & 0.009 & 0.128 & 0.942 & -0.001 & 0.010 & 0.887 \\
\hline Malay, female & -1.486 & 0.380 & $<0.001$ & -0.384 & 0.143 & 0.008 & -0.667 & 0.181 & $<0.001$ & -0.067 & 0.018 & $<0.001$ \\
\hline Chinese, female & -1.144 & 0.240 & $<0.00 \mathrm{I}$ & -0.530 & 0.100 & $<0.001$ & -0.650 & 0.125 & $<0.001$ & -0.067 & 0.012 & $<0.001$ \\
\hline Indian, female & -0.803 & 0.775 & 0.310 & -0.169 & 0.301 & 0.580 & -0.524 & 0.386 & 0.186 & -0.036 & 0.039 & 0.369 \\
\hline Overall, female & -1.136 & 0.193 & $<0.001$ & -0.438 & 0.077 & $<0.001$ & -0.607 & 0.097 & $<0.001$ & -0.060 & 0.010 & $<0.001$ \\
\hline
\end{tabular}

Abbreviations: B, unstandardized regression coefficient; BUA, broadband ultrasound attenuation; SE, standard error of regression coefficient; SOS, speed of sound.

In addition, bone health status of the subjects differed significantly by age groups in females but not in males $(P<0.05)$. The proportion of females classified as osteoporotic increased significantly in the older age group but this was not observed in males. Overall, $44.2 \%$ of the males and $35.3 \%$ of the females studied were osteopenic, while $10.6 \%$ of the males and $8.1 \%$ of the females were osteoporotic (Table 4 ). There was no difference in terms of bone health among the three ethnic groups studied $(P>0.05)$ (Table 5).

\section{Discussion}

The prevalence of osteoporosis is surging in the developing countries due to the increase in lifespan and elderly population. ${ }^{24}$ Despite this, information on bone health status of the Malaysian population, which is important for assessing the health care burden of osteoporosis and health policy making, is limited. The current study revealed that a significant proportion of Malaysian males (54.8\%) and females (43.4\%) had suboptimal bone health. Despite the higher prevalence of suboptimal bone health in males compared to females, the age-related decline of bone health indices was not significant in males. Ethnic differences in bone health were not observed in the study population as the age-related decline of bone health indices and the prevalence of suboptimal bone health were uniform across all three ethnic groups.

There were several small-scale studies determining the prevalence of osteoporosis in the Malaysian population using QUS. Most studies only recruited female subjects. ${ }^{18-20}$ A study by Hasnah et a $\mathrm{l}^{19}$ reported that among the 125 postmenopausal Malay females (mean age: 59 years [SD: 4] years) assessed using a QUS device, 6\% were osteoporotic and $37 \%$ were osteopenic. Damodaran et al ${ }^{18}$ observed that among 164 perimenopausal and postmenopausal females attending a menopause clinic, only four (2.44\%) were osteoporotic. The low prevalence could be due to the fact that those attending the menopause clinic were health conscious individuals. A previous study conducted by Chin et $\mathrm{al}^{17}$ on Malaysian males using a QUS device (mean age: 47.9 years [SD: 14.3 years]) identified that the prevalence of osteopenia was $21.3 \%$ and osteoporosis was $2.6 \%$. This was lower compared to the findings of the current study, whereby $45.2 \%$ of males were classified as osteopenic and $10.6 \%$ were classified as osteoporotic. Besides, Chin et $\mathrm{al}^{17}$ reported no significant difference in SOS value between Chinese and Malay males

Table 4 Bone health of the subjects according to sex and age groups

\begin{tabular}{|c|c|c|c|c|c|c|c|c|c|c|c|c|c|c|c|c|c|c|}
\hline \multirow{3}{*}{ Age group } & \multicolumn{9}{|c|}{ Male } & \multicolumn{9}{|c|}{ Female } \\
\hline & \multicolumn{2}{|c|}{ Normal } & \multicolumn{2}{|c|}{ Osteopenia } & \multicolumn{2}{|c|}{ Osteoporosis } & \multicolumn{2}{|c|}{ Total } & \multirow[t]{2}{*}{$P$-value } & \multicolumn{2}{|c|}{ Normal } & \multicolumn{2}{|c|}{ Osteopenia } & \multicolumn{2}{|c|}{ Osteoporosis } & \multicolumn{2}{|c|}{ Total } & \multirow[t]{2}{*}{$P$-value } \\
\hline & $\mathbf{n}$ & $\%$ & $\mathbf{n}$ & $\%$ & $\mathbf{n}$ & $\%$ & $\mathbf{n}$ & $\%$ & & $\mathbf{n}$ & $\%$ & $\mathbf{n}$ & $\%$ & $\mathbf{n}$ & $\%$ & $\mathbf{n}$ & $\%$ & \\
\hline $50-54$ years & 17 & 45.9 & 16 & 43.2 & 4 & 10.8 & 37 & 100 & 0.323 & 52 & 75.4 & 15 & 21.7 & 2 & 2.9 & 69 & 100 & $<0.001$ \\
\hline $55-59$ years & 25 & 55.6 & 16 & 35.6 & 4 & 8.9 & 45 & 100 & & 55 & 59.1 & 35 & 37.6 & 3 & 3.2 & 93 & 100 & \\
\hline 60-64 years & 39 & 30.5 & 36 & 44.4 & 6 & 7.4 & 81 & 100 & & 53 & 60.2 & 32 & 36.4 & 3 & 3.4 & 88 & 100 & \\
\hline 65-69 years & 21 & 32.3 & 33 & 50.8 & 11 & 16.9 & 65 & 100 & & 25 & 47.2 & 23 & 43.4 & 5 & 9.4 & 53 & 100 & \\
\hline 70-74 years & 17 & 53.1 & II & 34.4 & 4 & 12.5 & 32 & 100 & & 14 & 38.9 & 13 & 36.1 & 9 & 25 & 36 & 100 & \\
\hline $\begin{array}{l}75 \text { years or } \\
\text { above }\end{array}$ & 9 & 39.1 & 13 & 56.5 & 1 & 4.3 & 23 & 100 & & 6 & 26.1 & 10 & 43.5 & 7 & 30.4 & 23 & 100 & \\
\hline Overall & 128 & 45.2 & 125 & 44.2 & 30 & 10.6 & 283 & 100 & & 205 & 56.6 & 128 & 35.4 & 29 & 8 & 362 & 100 & \\
\hline
\end{tabular}

Notes: Quantitative ultrasound is not a diagnostic tool for osteoporosis. The T-score generated by QUS is different from T-score based on BMD obtained from DEXA. Pertaining to this study, the term "normal" indicates a low risk for osteoporosis, "osteopenia" indicates a moderate risk for osteoporosis, and "osteoporosis" indicates a high risk for osteoporosis.

Abbreviations: BMD, bone mineral density; DEXA, dual-energy X-ray absorptiometry; QUS, quantitative ultrasound. 
Table 5 Bone health of the subjects according to sex and ethnicity

\begin{tabular}{|c|c|c|c|c|c|c|c|c|c|c|c|c|c|c|c|c|c|c|}
\hline \multirow{3}{*}{$\begin{array}{l}\text { Bone health } \\
\text { status }\end{array}$} & \multicolumn{9}{|c|}{ Male } & \multicolumn{9}{|c|}{ Female } \\
\hline & \multicolumn{2}{|c|}{ Malay } & \multicolumn{2}{|c|}{ Chinese } & \multicolumn{2}{|c|}{ Indian } & \multicolumn{2}{|c|}{ Overall } & \multirow[t]{2}{*}{$P$-value } & \multicolumn{2}{|c|}{ Malay } & \multicolumn{2}{|c|}{ Chinese } & \multicolumn{2}{|c|}{ Indian } & \multicolumn{2}{|c|}{ Overall } & \multirow[t]{2}{*}{$P$-value } \\
\hline & $\mathbf{n}$ & $\%$ & $\mathbf{n}$ & $\%$ & $n$ & $\%$ & $\mathbf{n}$ & $\%$ & & n & $\%$ & $\mathbf{n}$ & $\%$ & $n$ & $\%$ & $\mathbf{n}$ & $\%$ & \\
\hline Normal & 52 & 47.3 & 59 & 42.1 & 17 & 51.5 & 128 & 45.2 & 0.299 & 71 & 57.3 & 118 & 56.7 & 16 & 53.3 & 205 & 56.6 & 0.499 \\
\hline Osteopenia & 51 & 46.4 & 63 & 45 & 11 & 33.3 & 125 & 44.2 & & 47 & 37.9 & 71 & 34.1 & 10 & 33.3 & 128 & 35.4 & \\
\hline Osteoporosis & 7 & 6.4 & 18 & 12.9 & 5 & 15.2 & 30 & 10.6 & & 6 & 4.8 & 19 & 9.1 & 4 & 13.3 & 29 & 8.0 & \\
\hline Total & 110 & 100 & 140 & 100 & 33 & 100 & 283 & 100 & & 124 & 100 & 208 & 100 & 30 & 100 & 362 & 100 & \\
\hline
\end{tabular}

Notes: Quantitative ultrasound is not a diagnostic tool for osteoporosis. The T-score generated by QUS is different from T-score based on BMD obtained from DEXA. Pertaining to this study, the term "normal" indicates a low risk for osteoporosis, "osteopenia" indicates a moderate risk for osteoporosis, and "osteoporosis" indicates a high risk for osteoporosis.

Abbreviations: BMD, bone mineral density; DEXA, dual-energy X-ray absorptiometry; QUS, quantitative ultrasound.

in Malaysia, which was similar to this study. However, a significant decline of SOS was documented in Chinese and Malay males after the age of 30 years..$^{17}$ This was different from our study, which found no significant age-related decline in bone health indices in males. The discrepancy might be due to the limited age range included (50 years and above) compared to their studies (20 years and above). Besides, the sample size in this study is only moderate and may not be capable of detecting the gradual change in bone health of males. No other studies the male osteoporosis in Malaysia were performed thus far, showing that this problem has been constantly overlooked by the medical and scientific community.

Among the 514 Malaysian urban female subjects (mean age: 51.07 years [SD: 5.28 years]) examined using DEXA, Lim et $\mathrm{a}^{25}$ found that the prevalence of osteoporosis was $8.6 \%$ based on spine BMD and $21.4 \%$ based on hip BMD, while the prevalence of osteopenia was $38.9 \%$ and $51.6 \%$, respectively. The estimates were similar to the findings of this study, whereby $8 \%$ of the female were osteoporotic and $35.4 \%$ were osteopenic. Lim et a ${ }^{25}$ also reported no ethnic differences in the prevalence of osteoporosis/osteopenia established based on BMD in Malaysian females. The prevalence of osteoporosis/osteopenia reported was $16.9 \%$ in the Malays, $27.4 \%$ in the Chinese, and $18.2 \%$ in the Indians based on either spine or hip BMD. ${ }^{25}$ This was higher than our estimates, which were $4.8 \%$ in the Malays, $9.1 \%$ in the Chinese, and $13.3 \%$ in the Indian. However, one should be cautious in comparing prevalence derived from QUS and DXA because discrepancy might exist. ${ }^{20}$

The third National Health and Nutrition Examination Survey revealed that there were significant differences in the prevalence of osteoporosis and osteopenia established based on BMD among the ethnic groups in the US. The prevalence was the highest in non-Hispanic Whites, followed by Mexican Americans and non-Hispanic Blacks. ${ }^{14}$ This was in accordance with their BMD values assessed by DEXA, which was the highest among the non-Hispanic Blacks, followed by Mexican Americans and non-Hispanic Whites. ${ }^{26}$ Similar to the US, Malaysia consists of three major ethnic groups and ethnic differences in the distribution of diseases were observed. ${ }^{10,27,28}$ Previous reports on fragility fractures in Malaysia in the year 1997 revealed that the incidence rate was the highest among the Chinese (males 94/100,000; females 220/100,000) and Indians (males 98/100,000; females 204/100,000) and several folds lower in the Malays (males 27/100,000; females 43/100,000). ${ }^{10,29}$ In Singapore with a similar ethnic composition as Malaysia, the incidence of fragility fracture was the highest among the Chinese (males $180 / 100,000$; females 437/100,000), followed by the Indians (males 198/100,000; females 242/100,000) and the lowest in the Malays (males 97/100,000; females 233/100,000). ${ }^{29}$ In contrast, the results of this study revealed no significant ethnic difference in the prevalence of osteoporosis/osteopenia and bone health indices for both sexes. The discrepancy between hip fracture incidence and bone health indices/prevalence of suboptimal bone health in terms of ethnic differences could be attributed to several reasons. Firstly, there are many predictors of falls and fragility fracture other than bone density, such as muscle weakness, gait and balance deficits, visual and cognitive impairments, and postural hypotension. ${ }^{30}$ Thus, variations in bone health alone could not explain the differences in fracture risk incidence among the ethnic groups. Secondly, assimilation and secular changes in the lifestyle among these ethnic groups during the period between the fracture incidence data first put forward (1997) $)^{10}$ and this study (2015) could have contributed to the discrepancy.

The age-related reduction in bone health indices and increase in prevalence of osteoporosis were significant in females but not in males in this study. Males have higher peak bone mass compared to females due to a higher rate of periosteal apposition. ${ }^{31}$ Besides, females universally experience the cessation of estrogen production after menopause, leading to rapid deterioration of bone health. ${ }^{32}$ Testosterone 
level declines gradually in males and testosterone deficiency syndrome is not universal, thus the deterioration of bone health in males is less severe. ${ }^{33}$ While the significant agerelated decline of QUS indices in females of this study was similar to previous reports, ${ }^{13,34,35}$ the decline was merely marginal in male subjects. Significant decline of QUS indices in males was documented in some studies involving wider age range, ${ }^{36-38}$ but in other studies, the decline was marginal or observed at the very late in life. ${ }^{13,39}$ This is in line with the fracture incidence of Malaysian males, which did not increase significantly until males were over 75 years. ${ }^{10}$

\section{Limitations}

This study is not without its limitations. A nonrandomized sampling technique was used; hence, generalization of the findings of this study should be done with caution. However, the ethnic composition recruited was similar to that of Kuala Lumpur as reported in the latest census. This study was crosssectional in nature; hence, the rate of age-related decline in bone health might differ from longitudinal observations. The reference value of mainland Chinese was used in our device because there is no local reference. This might create some discrepancies in the classification of subjects into different risk groups according to T-score based on SI. The study is notable because it is the first to access bone health of Malaysian males and females aged 50 years and above concurrently. All three major ethnic groups in Malaysia were represented in this study. The analysis was adjusted with BMI, which is a major confounding factor in bone health, ${ }^{40}$ to depict a more accurate decline of bone health with age in the subjects.

\section{Conclusion}

In conclusion, a significant proportion of elderly males and females living in Kuala Lumpur are facing the problem of osteoporosis and osteopenia. Therefore, both sexes deserve equal attention in the prevention and treatment of osteoporosis. Bone health in the Malaysian elderly shows a significant sex but not ethnic difference. However, true differences in rate of bone loss between sexes and ethnic groups await validation from comprehensive longitudinal studies. As the demographic trends of the nation are approaching that of a developed nation characterized by a high proportion of elderly in the population, preventive measures should be taken to slow down the progression of osteoporosis for minimizing the health care and economic burden. In this case, QUS may be useful in enabling early detection of osteoporosis because it can identify the age-related decline in bone health. Our study has contributed to filling the gap in the knowledge of bone health in Malaysia, but more updated data on bone health are needed to establish strategies to prevent osteoporosis in Malaysian elderly.

\section{Acknowledgments}

We thank Mr Fadlullah Zuhair Japar Sidik, Ms Juliana Abdul Hamid, Ms Nurul Hafizah Abas, Ms Sabariah Adnan, Mr Azlan Mohd Arslamsyah, Mr Mustazil Mohd Noor, Ms Nur Farhana Mohd Fozi, Ms Siti Zulfarina Mohamed and Mr Sharkawi Ahmad from the Department of Pharmacology, and Ms Sharifah Nurul Aqilah Sayed Mohd Zaris from the Department of Orthopaedic and Traumatology, Universiti Kebangsaan Medical Centre, who offered invaluable assistance in the screening sessions. Universiti Kebangsaan Malaysia funded this study via grants FF-2015-412 and FF-2015-396.

\section{Disclosure}

The authors report no conflicts of interest in this work.

\section{References}

1. Edwards MH, Dennison EM, Aihie Sayer A, Fielding R, Cooper C. Osteoporosis and sarcopenia in older age. Bone. 2015;80:126-130.

2. Schuit SC, van der Klift M, Weel AE, et al. Fracture incidence and association with bone mineral density in elderly men and women: the Rotterdam Study. Bone. 2004;34(1):195-202.

3. World Health Organization. Assessment of fracture risk and its application to screening for postmenopausal osteoporosis. Report of a WHO study group. World Health Organ Tech Rep Ser. 1994;843:1-129.

4. Mithal A, Ebeling P. The Asia-Pacific Regional Audit: Epidemiology, Costs \& Burden of Osteoporosis in 2013. Nyon: International Osteoporosis Foundation; 2013.

5. Cavani F, Giavaresi G, Fini M, et al. Influence of density, elasticity, and structure on ultrasound transmission through trabecular bone cylinders. IEEE Trans Ultrason Ferroelectr Freq Control. 2008;55(7): 1465-1472.

6. Chan MY, Nguyen ND, Center JR, Eisman JA, Nguyen TV. Absolute fracture-risk prediction by a combination of calcaneal quantitative ultrasound and bone mineral density. Calcif Tissue Int. 2012;90(2): $128-136$.

7. Kwok T, Khoo CC, Leung J, et al. Predictive values of calcaneal quantitative ultrasound and dual energy $\mathrm{X}$ ray absorptiometry for nonvertebral fracture in older men: results from the MrOS study (Hong Kong). Osteoporos Int. 2012;23(3):1001-1006.

8. Padilla F, Jenson F, Bousson V, Peyrin F, Laugier P. Relationships of trabecular bone structure with quantitative ultrasound parameters: In vitro study on human proximal femur using transmission and backscatter measurements. Bone. 2008;42(6):1193-1202.

9. Chin KY, Ima-Nirwana S. Calcaneal quantitative ultrasound as a determinant of bone health status: what properties of bone does it reflect? Int J Med Sci. 2013;10(12):1778-1783.

10. Lee J-K, Khir ASM. The incidence of hip fracture in Malaysians above 50 years of age: variation in different ethnic groups. APLARJ Rheumatol. 2007;10(4):300-305.

11. Krassas GE, Papadopoulou FG, Doukidis D, Konstantinidis TH, Kalothetou K. Age-related changes in bone density among healthy Greek males. J Endocrinol Invest. 2001;24(5):326-333. 
12. Johnell O, Kanis J. An estimate of the worldwide prevalence and disability associated with osteoporotic fractures. Osteoporos Int. 2006; 17(12):1726-1733.

13. Maggi S, Noale M, Gonnelli S, et al. Quantitative ultrasound calcaneous measurements: normative data for the Italian population. the ESOPO study. J Clin Densitom. 2007;10(3):340-346.

14. Looker AC, Orwoll ES, Johnston CC, et al. Prevalence of low femoral bone density in older U.S. adults from NHANES III. J Bone Miner Res. 1997;12(11):1761-1768.

15. Looker AC, Melton LJ, Borrud LG, Shepherd JA. Lumbar spine bone mineral density in US adults: demographic patterns and relationship with femur neck skeletal status. Osteoporos Int. 2012;23(4):1351-1360.

16. Mithal A, Kaur P. Osteoporosis in Asia: a call to action. Curr Osteoporos Rep. 2012;10(4):245-247.

17. Chin KY, Soelaiman IN, Mohamed IN, et al. Discrepancy between the quantitative ultrasound value of Malaysian men and the manufacturer's reference and the impact on classification of bone health status. J Clin Densitom. 2013;16(2):189-195.

18. Damodaran P, Subramaniam R, Omar SZ, Nadkarni P, Paramsothy M. Profile of a menopause clinic in an urban population in Malaysia. Singapore Med J. 2000;41(9):431-435.

19. Hasnah H, Amin I, Suzana S. Bone health status and lipid profile among post-menopausal Malay women in Cheras, Kuala Lumpur. Malays J Nutr. 2012;18(2):161-171.

20. Zaini WM, Md Ariff A. Bone mineral density assessment in pre- and postmenopausal women: comparison between t-scores by heel QUS and DXA in HRPZII. Med J Malaysia. 2012;67(5):487-490.

21. Department of Statistics Malaysia. Population Distribution and Basic Demographic Characteristic Report 2010. 2011. Available from: https://www. statistics.gov.my/index.php?r=column/cthemeByCat\&cat=117\&bul_id =MDMxdHZjWTk1SjFzTzNkRXYzcVZjdz09\&menu_id=L0pheU43 NWJwRWVSZklWdzQ4TlhUUT09. Accessed January 31, 2016.

22. Krieg MA, Barkmann R, Gonnelli S, et al. Quantitative ultrasound in the management of osteoporosis: the 2007 ISCD official positions. J Clin Densitom. 2008;11(1):163-187.

23. Holi MS, Radhakrishnan S, Swaranamani S, Jayavelan NA. Quantitative ultrasound technique for the assessment of osteoporosis and prediction of fracture risk. J Pure Appl Ultrason. 2005;27:55-60.

24. Handa R, Ali Kalla A, Maalouf G. Osteoporosis in developing countries. Best Pract Res Clin Rheumatol. 2008;22(4):693-708.

25. Lim PS, Ong FB, Adeeb N, et al. Bone health in urban midlife Malaysian women: risk factors and prevention. Osteoporos Int. 2005;16(12): 2069-2079.
26. Looker AC, Borrud LG, Hughes JP, Fan B, Shepherd JA, Melton LJ 3rd Lumbar spine and proximal femur bone mineral density, bone mineral content, and bone area: United States, 2005-2008. Vital Health Stat 11. 2012;(251):1-132.

27. Letchuman GR, Wan Nazaimoon WM, Wan Mohamad WB, et al. Prevalence of diabetes in the Malaysian national health morbidity survey III 2006. Med J Malaysia. 2010;65(3):180-186.

28. Zainal Ariffin O, Nor Saleha IT. National Cancer Registry Report: Malaysia Cancer Statistics - Data and Figure 2007. Putrajaya: Ministry of Health Malaysia; 2011.

29. Lau EM, Lee JK, Suriwongpaisal P, et al. The incidence of hip fracture in four Asian countries: the Asian Osteoporosis Study (AOS). Osteoporos Int. 2001;12(3):239-243.

30. Rubenstein LZ. Falls in older people: epidemiology, risk factors and strategies for prevention. Age Ageing. 2006;35(Suppl 2):ii37-ii41.

31. Duan Y, Turner CH, Kim BT, Seeman E. Sexual dimorphism in vertebral fragility is more the result of gender differences in age-related bone gain than bone loss. J Bone Miner Res. 2001;16(12):2267-2275.

32. Riggs BL, Khosla S, Melton LJ. Sex steroids and the construction and conservation of the adult skeleton. Endocr Rev. 2002;23(3):279-302.

33. Chin KY, Ima-Nirwana S. Sex steroids and bone health status in men Int J Endocrinol. 2012;2012:208719.

34. Pluskiewicz W. Bone status assessed by quantitative ultrasound in healthy postmenopausal Polish women: normative data. Clin Rheumatol. 1998; 17(1):40-43

35. Trovas G, Tsekoura M, Galanos A, et al. Quantitative ultrasound of the calcaneus in Greek women: normative data are different from the manufacturer's normal range. J Clin Densitom. 2009;12(3):353-359.

36. VanderJagt DJ, Damiani LA, Goodman TM, et al. Assessment of the skeletal health of healthy Nigerian men and women using quantitative ultrasound. Bone. 2004;35(2):387-394.

37. Zhang ZL, Qin YJ, Huang QR, et al. Bone mineral density of the spine and femur in healthy Chinese men. Asian J Androl. 2006;8(4):419-427.

38. Zhu ZQ, Liu W, Xu CL, Han S-M, Zu SY, Zhu GJ. Reference data for quantitative ultrasound values of calcaneus in 2927 healthy Chinese men. J Bone Miner Metab. 2008;26(2):165-171.

39. Kastelan D, Kujundzic-Tiljak M, Kraljevic I, Kardum I, Giljevic Z, Korsic M. Calcaneus ultrasound in males: normative data in the Croatian population (ECUM study). J Endocrinol Invest. 2006;29(3):221-225.

40. Chin KY, Soelaiman IN, Mohamed IN, Ibrahim S, Ngah WZW. The effects of age, physical activity level, and body anthropometry on calcaneal speed of sound value in men. Arch Osteoporos. 2012;7(1-2): $135-145$.
Clinical Interventions in Aging

\section{Publish your work in this journal}

Clinical Interventions in Aging is an international, peer-reviewed journal focusing on evidence-based reports on the value or lack thereof of treatments intended to prevent or delay the onset of maladaptive correlates of aging in human beings. This journal is indexed on PubMed Central, MedLine,

\section{Dovepress}

CAS, Scopus and the Elsevier Bibliographic databases. The manuscript management system is completely online and includes a very quick and fair peer-review system, which is all easy to use. Visit http://www.dovepress. com/testimonials.php to read real quotes from published authors. 